\title{
Conservative management of a periradicular lesion associated with a palatogingival groove
}

\author{
Hakan Arslan, ${ }^{1}$ Serhat Köseoğlu, ${ }^{2}$ Hazal Ergün,, ${ }^{3}$ Elif Tarım Ertaş ${ }^{4}$ \\ 'Department of Endodontics, Ataturk University Faculty of Dentistry, Erzurum, Turkey \\ ${ }^{2}$ Department of Periodontology, Izmir Katip Çelebi University Faculty of Dentistry, İzmir, Turkey \\ ${ }^{3}$ Department of Endodontics, Izmir Katip Çelebi University Faculty of Dentistry, Izmir, Turkey \\ ${ }^{4}$ Department of Oral Diagnosis and Radiology, Izmir Katip Çelebi University Faculty of Dentistry, Izmir, Turkey
}

\begin{abstract}
The aim of this case report was to present the management of a periradicular lesion and the maintenance of pulp vitality following surgical odontoplasty in a maxillary lateral incisor with a palatogingival groove (PGG). A case of PGG in the maxillary left lateral incisor with vital pulp and a large periradicular lesion is reported. Surgical odontoplasty of the PGG and restoration of the coronal part of the PGG were performed without root canal treatment. Follow-up revealed that the pulp responded to cold test in the same manner as prior to treatment and the periradicular lesion was resolved. In cases where the apical pathosis includes the apical part of the root, the tooth should be evaluated using pulp vitality tests to determine whether the pulp is healthy. A tooth with vital pulp and periapical radiolucency should raise the suspicion of morphological changes, such as a PGG, in the tooth. A detailed examination of the tooth should be performed. Cone-beam computed tomography could be beneficial in making a definitive diagnosis.
\end{abstract}

Keywords: Odontoplasty; palatogingival groove; periradicular lesion; vital pulp.

$\mathrm{T}$ The palatogingival groove (PGG) is a developmental malformation that occurs near the cingulum of a tooth and extends along the root to varying lengths. ${ }^{[1,2]}$ This malformation is known by different names, including the radicular groove, ${ }^{[3]}$ a palatal groove, ${ }^{[4]}$ a radicular lingual groove, ${ }^{[5]}$ a disto-lingual groove, ${ }^{[6]}$ a vertical developmental radicular groove, ${ }^{[5]}$ a cinguloradicular groove, ${ }^{[7]}$ a developmental radicular anomaly, ${ }^{[8]}$ an interruption groove, ${ }^{[9]}$ and a coronoradicular groove. ${ }^{[10]}$ Although the exact etiology of PGGs remains unclear, alteration of genetic mechanisms, enfolding of the enamel organ and Hertwig's epithelial root sheath, and the effort required to form another root are considered as causal elements of PGG. ${ }^{[1,6,8,11]}$

$\mathrm{Gu}^{[11]}$ classified PGGs into three types according to the degree of severity based on microcomputed tomography studies: In type I, the groove is short (not beyond the coronal third of the root); in type II, the groove is long (beyond the coronal third of the root) but shallow, corresponding to a normal or simple root canal; in type III, the groove is long (beyond the coronal third of the root) and deep, corresponding to a complex root canal system.

PGGs are clinically significant because they allow bacterial plaque and calculus to accumulate, thereby aiding

Correspondence: Dr. Hakan Arslan. Atatürk Üniversitesi Diş Hekimliği Fakültesi,

Endodonti Anabilim Dalı, Erzurum, Turkey.

Tel: +905339351238 e-mail: dt_hakan82@hotmail.com

Submitted: February 22, 2015 Accepted: July 16, 2015 
the development of localized periodontitis. ${ }^{[1]}$ Long PGGs, which reach the apical foramen, can cause a secondary pulp infection followed by a periapical lesion in some cases. ${ }^{[12]}$ Deep grooves can also connect with the pulp cavity, resulting in a pulp infection. ${ }^{[13]}$ Pulp infections can be primary, followed by an endodontic lesion advancing through the PGG. ${ }^{[3]}$ The main accessory canals form a link between the pulp and the PGG. ${ }^{[12]}$

The clinical management of PGGs may be difficult. Case reports have described several treatment modalities to eliminate PGGs, such as odontoplasty, resection of accessory roots, intentional replantation, periodontal regeneration, and extraction. ${ }^{[14-18]}$ Other studies used restorative materials, such as amalgam, glass ionomer cement, and composites, to fill the PGG. ${ }^{[12,19,20]}$ The treatment options vary according to the presence and the depth of the pulp cavity. If the pulp is infected, root canal treatment should be initiated. The purpose of this article is to report a case of PGG in a maxillary lateral incisor with a large periradicular lesion in which only the PGG was treated. Odontoplasty and restoration of the coronal part of the PGG maintained the pulp vitality and resulted in resolution of the clinical symptoms and the periradicular lesion.

\section{Case report}

A 38-year-old male was referred to the Department of Endodontics for dental treatment. He reported that swelling had previously occurred in the region of the maxillary anterior teeth. There were no other clinical signs or symptoms or notable medical history. Radiographic examination of the radiographs, which were taken previously in the Department of Oral and Maxillofacial Radiology, revealed a periradicular lesion around the apex of the left maxillary lateral incisor (Fig. la and b).

An intraoral examination revealed caries on the distal surface of the left maxillary lateral incisor. There was also abscess drainage from the gingival sulcus (Fig. lc and d). PGG was noted on the palatal surface of the tooth (Fig. le). The tooth responded to pulp sensitivity testing using ice and an electrical pulp tester, which was similar to bilateral tooth. Tooth 12 was not tender to percussion, and the labial mucosa of the tooth 12 was not tender to palpation. Probing depth scores were high in the mesiobuccal and midpalatinal sides of the tooth 12 (12 and $7 \mathrm{~mm}$, respectively) (Fig ld). The tooth had moderate mobility (grade 2 , horizontal direction of $>1 \mathrm{~mm}$ ).

After obtaining the approval of the patient, a conebeam computed tomography was taken for three-dimensional evaluation. It showed a PGG extending along the root and a large periradicular lesion (Fig. 2, 3). The clinical and radiographic examination suggested a diagnosis of chronic periodontitis associated with the PGG. Thus, a decision was taken to perform surgical odontoplasty without endodontic treatment. Scaling and root planning were performed because of poor oral hygiene. The caries were then removed, and the cavity was restored with composite resin.

Following local anaesthesia, a buccal mucoperiosteal and a palatal envelope flap were elevated (Fig. 2a and b). An extended apical osseous defect associated with the complete loss of the mesial alveolar bone wall of the lateral tooth was seen. Root planning and bone defect debridement were performed (Fig. $2 \mathrm{c}$ and d) avoiding damage to periradicular area. The coronal part of the planed PGG was also restored with composite resin. The mesial bone defect was completely filled with a deproteinized bovine bone mineral (Bio-Oss, Geistlich Pharma, Wolhusen, Switzerland) (Fig 2e), and then all the borders of the
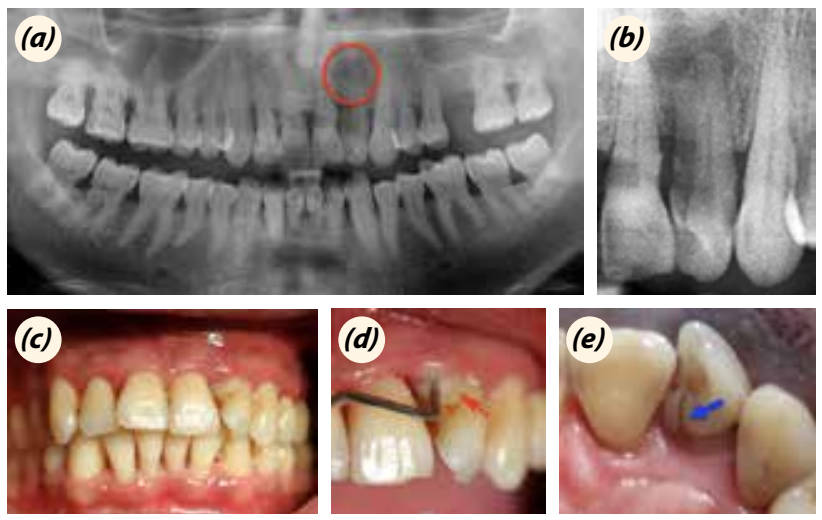

Fig. 1. (a, b) show periradicular lesion, $(\mathbf{c}, \mathbf{d})$ show abscess drainage, and (e) shows PGG. Red arrow indicates the abscess drainage, and blue arrow indicates the intra-oral view of the PGG.
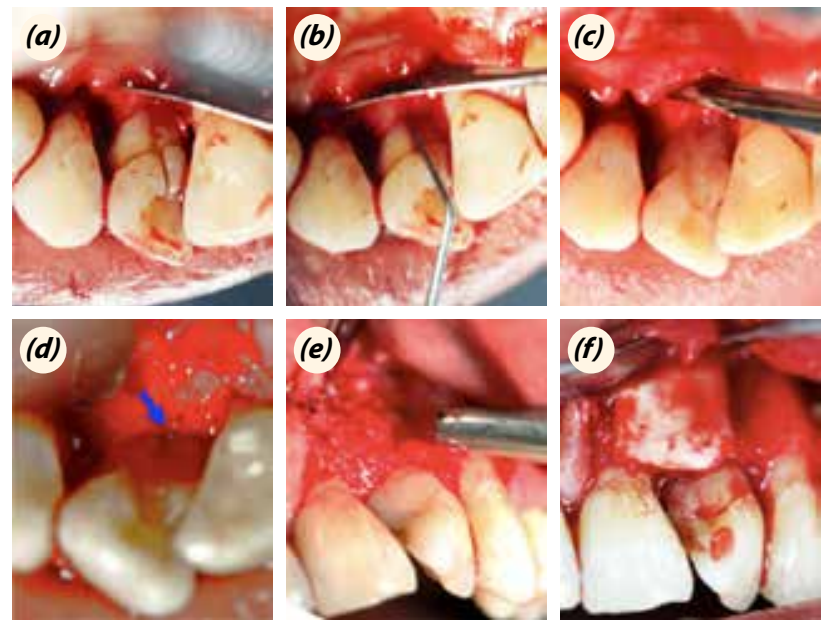

Fig. 2. Summary of surgical procedure. Exposure of PGG (a, b), odontoplasty (c, d), filling with a deproteinized bovine bone mineral (e), and covering with a trimmed collagen membrane (f) -arrow indicates extending of PGG to the apical region. 

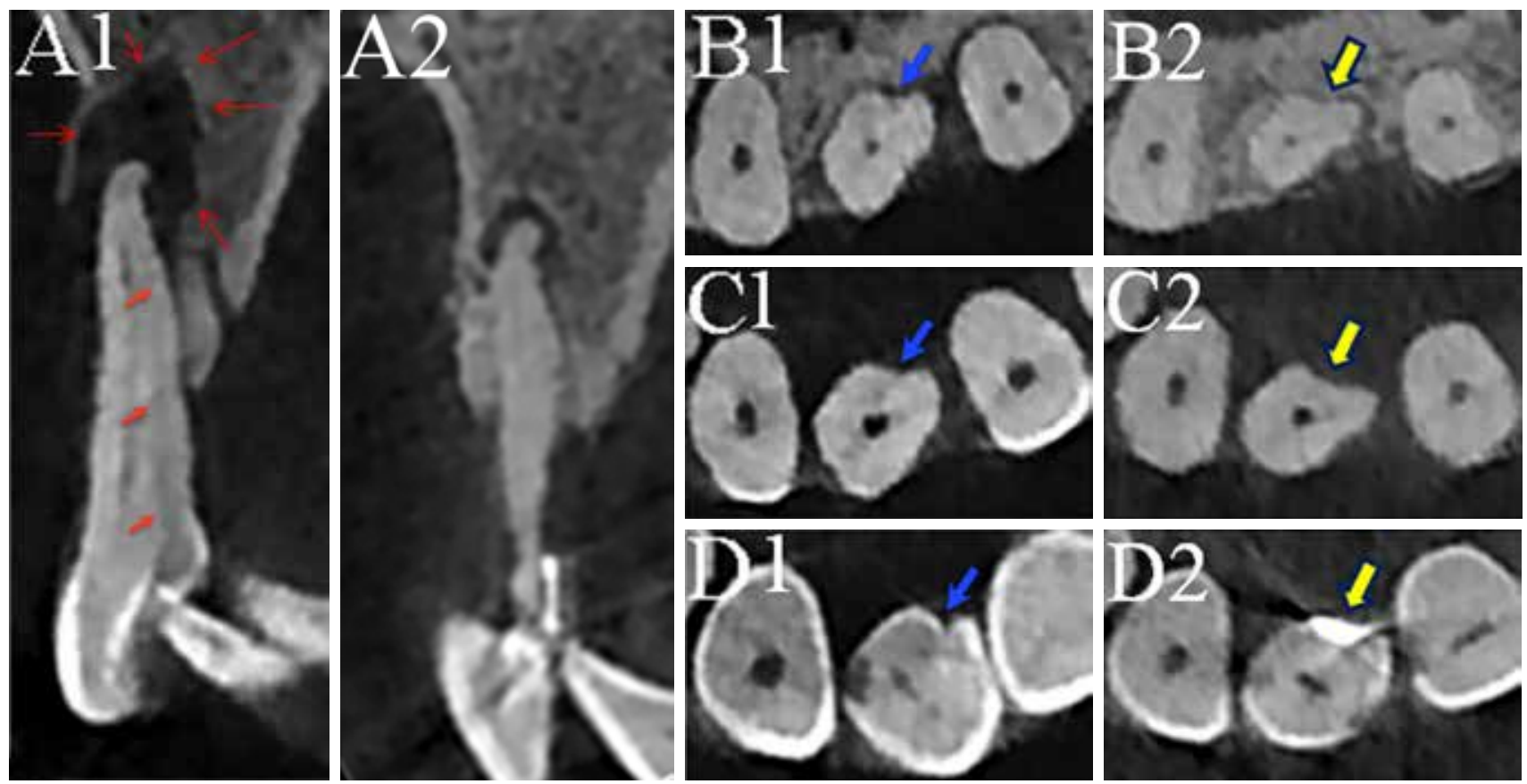

Fig. 3. Shows PGG and periradicular lesion in different plans. (A1) shows the preoperative CBCT view of periapical lesion and PGG, (A2) shows the healing of the periapical lesion without root canal treatment at 10 months. (B1, C1 and D1) indicate preoperative (B2, C2 and D2) indicate postoperative CBCT views.

lesion were covered with a trimmed collagen membrane (Collagene AT, Centro di Odontoiatria Operative, Padova, Italy) (Fig 2f). The flaps were closed with 5-0 silk and 6-0 nylon sutures. The patient was prescribed antibiotics (Augmentin, GlaxoSmithKline, Middlesex, U.K.) (625 g amoxicillin, twice daily for 7 days, starting the day before surgery) and an antimicrobial spray (Klorhex, Drogsan, Istanbul, Turkey) ( $0.2 \%$ chlorhexidine, 3 times daily for 14 days). The patient was recalled after 7 days for suture removal. He was re-evaluated weekly for the first month and monthly thereafter. Oral hygiene instructions were reinforced if necessary at each appointment.

A clinical examination 10 months after the procedures revealed that the tooth responded to ice and electrical pulp vitality testing and that the patient remained asymptomatic. A CBCT examination revealed that the periradicular lesion had almost disappeared. After the treatment, all the pathological periodontal pockets were resolved, and the mobility grade decreased from 2 to $<1$.

\section{Discussion}

The prevalence of PGGs ranges from $1.01 \%$ to $18 \%$. ${ }^{[6,21-23]} \mathrm{A}$ study by Bacić et al. ${ }^{[4]}$ indicated that $1.01 \%$ of extracted maxillary incisors investigated presented with a PGG, whereas $\operatorname{Kogon}^{[21]}$ and Pécora et al. ${ }^{[24]}$ reported a prevalence of $4.6 \%$ and $3.9 \%$, respectively. PGGs are usually found in the maxillary lateral incisors and occur less frequently in the central incisors. ${ }^{[6,24]}$ They normally originate in the central fossa, pass the cingulum, and spread through the root in different directions and distances. ${ }^{[21]}$ The region around the maxillary lateral incisor is an area of embryological hazard. ${ }^{[6]} \mathrm{A}$ great number of malformations occur in this region, namely, globulo-maxillary cysts, ${ }^{[25]}$ and cleft palate, ${ }^{[26]}$ as well as missing, ${ }^{[27]}$ supernumerary, ${ }^{[28]}$ dens invaginatus, ${ }^{[29]}$ or peg-shaped lateral incisors. ${ }^{[30]}$ Case reports have presented maxillary lateral incisors with PGGs that needed endodontic and periodontal management. ${ }^{[12,31]}$

Different treatment approaches has been performed to manage PGG. Wei et al. ${ }^{[14]}$ treated the tooth with PGG by conventional endodontic therapy in combination with periodontal treatment including accessory root resection, odontoplasty and bone grafting. Al-Hezaimi et al. ${ }^{[15]}$ performed a combination of endodontic, intentional replantation and Emdogain therapy. Similarly, Rethman ${ }^{[16]}$ performed periodontal surgery, odontoplasty, citric acid application, and Emdogain therapy. Anderegg and Metzler $^{[17]}$ performed removal of granulation tissue, and scaling and root planning of the groove.

The management of PGG that extends apically and results in periradicular lesions generally involves elimination of the PGG and root canal treatment. ${ }^{[12,13]}$ The patient in this report presented with a maxillary lateral tooth with vital pulp, a PGG, and a periradicular lesion. Apical exten- 
sion of the PGG may explain the occurrence of the periradicular lesion. However, it was more likely due to blood vessel and nerve damage because the pulp remained vital.

In this case, as the depth of the PGG was not extensive, only odontoplasty was performed. The coronal part of the PGG was flattened and restored with composite resin. Care should be taken not to damage blood vessels and nerves during procedures performed in the periradicular area. In the current case, the combination of deproteinized bovine bone mineral and collagen membrane was selected because of the size of the osseous defect.

\section{Conclusion}

The aim of this case report was to describe the maintenance of pulp vitality in a tooth with a periradicular lesion and PGG. Management without root canal treatment could be considered as an alternative procedure in selected cases.

Conflics of Interest: No conflicts declared.

\section{References}

1. Lee KW, Lee EC, Poon KY. Palato-gingival grooves in maxillary incisors. A possible predisposing factor to localised periodontal disease. Br Dent J 1968;124:14-8.

2. Arslan H, Ertas ET, Topçuoğlu HS, Şekerci AE, Atici MY, Ertas $\mathrm{H}$, et al. Radicular grooves of maxillary anterior teeth in a Turkish population: a cone-beam computed tomographic study. Arch Oral Biol 2014;59:297-301.

3. Simon JH, Dogan H, Ceresa LM, Silver GK. The radicular groove: its potential clinical significance. J Endod 2000;26:295-8.

4. Bacić M, Karakas Z, Kaić Z, Sutalo J. The association between palatal grooves in upper incisors and periodontal complications. J Periodontol 1990;61:197-9.

5. Meister F Jr, Keating K, Gerstein H, Mayer JC. Successful treatment of a radicular lingual groove: case report. J En$\operatorname{dod} 1983 ; 9: 561-4$.

6. Everett FG, Kramer GM. The disto-lingual groove in the maxillary lateral incisor; a periodontal hazard. J Periodontol 1972;43:352-61.

7. Assaf ME, Roller N. The cingulo-radicular groove: its significance and management--two case report. Compendium 1992;13:94, 96, 98 passim.

8. Simon JH, Glick DH, Frank AL. Predictable endodontic and periodontic failures as a result of radicular anomalies. Oral Surg Oral Med Oral Pathol 1971;31:823-6.

9. Bollini GA, Rodríguez-Flórez CD, Colantonio SE. Bilateral asymmetry in permanent dentition of 13 pre-conquest samples from Argentina (South America). Homo 2009;60:127-37.

10. Liji MP, Rameshkumar M. Integration of PRF and bioden- tine in palatogingical groove case. OSR-JDMS 2013;6:2630.

11. Gu YC. A micro-computed tomographic analysis of maxillary lateral incisors with radicular grooves. J Endod 2011;37:789-92.

12. Attam K, Tiwary R, Talwar S, Lamba AK. Palatogingival groove: endodontic-periodontal management--case report. J Endod 2010;36:1717-20.

13. Cecília MS, Lara VS, de Moraes IG. The palato-gingival groove. A cause of failure in root canal treatment. Oral Surg Oral Med Oral Pathol Oral Radiol Endod 1998;85:94-8.

14. Wei PC, Geivelis M, Chan CP, Ju YR. Successful treatment of pulpal-periodontal combined lesion in a birooted maxillary lateral incisor with concomitant palato-radicular groove. A case report. J Periodontol 1999;70:1540-6.

15. Al-Hezaimi K, Naghshbandi J, Simon JH, Oglesby S, Rotstein I. Successful treatment of a radicular groove by intentional replantation and Emdogain therapy. Dent Traumatol 2004;20:226-8.

16. Rethman MP. Treatment of a palatal-gingival groove using enamel matrix derivative. Compend Contin Educ Dent 2001;22:792-7.

17. Anderegg CR, Metzler DG. Treatment of the palato-gingival groove with guided tissue regeneration. Report of 10 cases. J Periodontol 1993;64:72-4.

18. Peikoff MD, Perry JB, Chapnick LA. Endodontic failure attributable to a complex radicular lingual groove. J Endod 1985;11:573-7.

19. Friedman S, Goultschin J. The radicular palatal groove--a therapeutic modality. Endod Dent Traumatol 1988;4:2826.

20. Cortellini P, Pini Prato G, Tonetti MS. Periodontal regeneration of human infrabony defects. I. Clinical measures. J Periodontol 1993;64:254-60.

21. Kogon SL. The prevalence, location and conformation of palato-radicular grooves in maxillary incisors. J Periodontol 1986;57:231-4.

22. Withers JA, Brunsvold MA, Killoy WJ, Rahe AJ. The relationship of palato-gingival grooves to localized periodontal disease. J Periodontol 1981;52:41-4.

23. Hou GL, Tsai CC. Relationship between palato-radicular grooves and localized periodontitis. J Clin Periodontol 1993;20:678-82.

24. Pécora JD, da Cruz Filho AM. Study of the incidence of radicular grooves in maxillary incisors. Braz Dent J 1992;3:11-6.

25. Audion M, Siberchicot F. Globulomaxillary cyst. [Article in French] Rev Stomatol Chir Maxillofac 2010;111:25-6. [Abstract]

26. Suzuki A, Takahama Y. Maxillary lateral incisor of subjects with cleft lip and/or palate: Part 1. Cleft Palate Craniofac J 1992;29:376-9. 
27. Celikoglu M, Kamak H, Yildirim H, Ceylan I. Investigation of the maxillary lateral incisor agenesis and associated dental anomalies in an orthodontic patient population. Med Oral Patol Oral Cir Bucal 2012;17:1068-73.

28. Sharma A, Singh VP. Supernumerary teeth in Indian children: a survey of 300 cases. Int J Dent 2012;2012:745265.

29. Vier-Pelisser FV, Pelisser A, Recuero LC, Só MV, Borba MG, Figueiredo JA. Use of cone beam computed tomog- raphy in the diagnosis, planning and follow up of a type III dens invaginatus case. Int Endod J 2012;45:198-208.

30. Kook YA, Park S, Sameshima GT. Peg-shaped and small lateral incisors not at higher risk for root resorption. Am J Orthod Dentofacial Orthop 2003;123:253-8.

31. Schwartz SA, Koch MA, Deas DE, Powell CA. Combined endodontic-periodontic treatment of a palatal groove: a case report. J Endod 2006;32:573-8. 